\title{
Plasma 25-Hydroxy-vitamin D in Familial Hypercholesterolemic Children Receiving Colestipol Resin
}

\author{
REGINALD C. TSANG, MARTIN S. ROGINSKY, MARGOT J. MELLIES, AND CHARLES J. \\ GLUECK $^{(30)}$ \\ Department of Pediatrics and Medicine, Lipoprotein Research Laboratory and General Clinical Research Center, \\ Cincinnati General Hospital and Newborn Division, Children's Hospital Research Foundation, University of \\ Cincinnati, College of Medicine, Cincinnati, Ohio; and the Division of Endocrinology and Metabolism, Department of \\ Medicine, State University of New York, at Stoneybrook, Stoneybrook, New York, USA
}

\section{Summary}

In this study we have assessed effects of Colestipol, a synthetic organic bile sequestrant polymer, on vitamin D metabolism over a 2-year period in children with familial hypercholesterolemia. In the 15 children, mean $( \pm \mathrm{SE})$ low density lipoprotein (LDL) cholesterol decreased from $221 \pm 9 \mathrm{mg} / \mathrm{dl}$ (baseline), to $181 \pm 7$ after 12-14 months of Colestipol resin, $P<0.01$. Thereafter, LDL cholesterol remained in the $170-190 \mathrm{mg} / \mathrm{dl}$ range. Mean plasma 25-hydroxyvitamin D (25-OHD) levels appeared to fall slightly and progressively from $32.6 \pm 4 \mathrm{ng} / \mathrm{ml}$ (baseline) to $29.8 \pm 3.5$ at $12-14$ months, to $25.6 \pm 3.3$ at $16-18$ months, and to $18.5 \pm 2.7$ at $18-20$ months. The decrease in plasma 25-OHD was not significant until 18-20 months (paired $t, P<0.01$ ). After 20 months, plasma 25OHD levels appeared to increase again and were not significantly different from baseline. Seasonal effects on plasma 25-OHD were not demonstrable. Mean plasma $\mathrm{Ca}$ values were mildly increased after Colestipol therapy was begun and were significantly elevated at 18-20 months (10.04 vs. $9.71 \mathrm{mg} / \mathrm{dl}$ at baseline). Mean plasma $\mathrm{PO}_{4}$ levels were not significantly different on Colestipol therapy, with the single exception that at 20-22 months plasma $\mathrm{PO}_{4}$ was 3.82 vs. $4.05 \mathrm{mg} / \mathrm{dl}$ at baseline $(P<0.05)$. In no subject was serum $\mathrm{Ca}<9 \mathrm{mg} / \mathrm{dl}$ or serum $\mathrm{PO}_{4}<2.5 \mathrm{mg} / \mathrm{dl}$ at any time during the study.

\section{Speculation}

In children with familial hypercholesterolemia receiving bile acid sequestrants (10-15 g/day), consistent changes in $\mathrm{Ca}, \mathrm{PO}_{4}$, and 25-OHD levels appear to be unlikely, but long term monitoring of these factors would be important in regard to optimal growth and development.

Recently, emphasis has been placed on the diagnosis and therapy of hyperlipoproteinemias in children as a primary approach to prevention of premature atherosclerosis $(7,8,11-14,16,27,28)$. Anion exchange resins, Colestipol and Questran, have been recently introduced for use in children who have familial hypercholesterolemia, who are resistant to dietary management alone $(7,8$, $11,12,27,28)$.

When these resins are used for long term therapy in children, it is important to monitor for any effects on growth and development $(7,8,11,12,27,28)$. Concern has been raised about possible long term effects on nutrient absorption with the use of organic anion exchange resins which sequester bile and impair bile acid absorption (27).

In children receiving a high dose of cholestyramine resin $(0.6$ $\mathrm{g} / \mathrm{kg} /$ day), West and Lloyd reported decreased plasma $\mathrm{PO}_{4}(27)$.
Plasma calcium was increased during cholestyramine therapy in three patients studied by Briscoe (5). In rats, cholestyramine resin avidly binds enterohepatic recycled $25-\mathrm{OHD}_{3}(19,25)$. Within this frame of reference $(19,25)$, in this study we have assessed effects of Colestipol, a new synthetic organic bile sequestrant polymer (U26-597A) $(11,18)$ on vitamin D metabolism over a 2-year period in children with familial hypercholesterolemia.

\section{MATERIALS AND METHODS}

\section{PATIENTS}

Fifteen children (median age 15 years, range 7-20 years) were studied. Their hypercholesterolemia was documented as familial by the following three criteria: 1) fasting hyperbetalipoproteinemia in the child and one proband parent $(9,11-14,16) ; 2)$ exclusion of disorders causing secondary hypercholesterolemia $(9,13)$; and 3 ) the presence of hyperbetalipoproteinemia in one parent and in one or more siblings, confirming its familial nature $(9,11-14,16)$.

All spouses of the affected parents had normal levels of plasma cholesterol, LDL cholesterol, and triglyceride.

\section{DIAGNOSIS OF HYPERBETALIPOPROTEINEMIA}

For each child, two or three index blood samples were obtained after a 12- to 14-hr fast. The children were on their habitual ad libitum diets without any recent weight changes. There was a 2- to 3-week interval between the first and second index blood samples. Hyperlipoproteinemia was diagnozed by established, previously described methods $(7,13,14,16)$. Upper normal limits for plasma cholesterol and $\beta$-lipoprotein cholesterol in children were based on age-adjusted criteria $(9,11-14,16)$

\section{STUDY PROTOCOL}

Enrollment into the present study was in the consecutive order of presentation to the University of Cincinnati Lipid Research Center. A low cholesterol $(<300 \mathrm{mg} /$ day) and high polyunsaturate (P/S 1.5:1) diet was prescribed by metabolic dietitians. All children who were subsequently placed on Colestipol had persistent hyperbetalipoproteinemia on diet therapy alone (11). Colestipol resin $10-15 \mathrm{~g} /$ day (11) was given, one pack given with breakfast and one pack with the evening meal. Adherence to the drug was reviewed and reinforced at each visit. No specific dietary supplementation with vitamin $\mathrm{D}$ was advised.

Baseline pre-Colestipol, and follow-up samples on Colestipol at $12-14,16-18,18-20,20-22$, and 22-24 months were obtained (Table 1). At each visit, fasting blood samples were obtained for 
Table 1. Plasma LDL cholesterol, 25-hydroxy-vitamin D, Ca, and $\mathrm{PO}_{4}$ in children on Colestipol resin ${ }^{1}$

\begin{tabular}{|c|c|c|c|c|c|c|}
\hline & Baseline (15) & 12-14 Month (15) & 16-18 Month (11) & 18-20 Month (10) & 20-22 Month (6) & 22-24 Month (9) \\
\hline LDL cholesterol (mg/dl) & $221.4 \pm 8.8$ & $181 \pm 7.14^{2}$ & $191 \pm 10.17^{3}$ & $172.7 \pm 8.36^{2}$ & $189.5 \pm 18.88^{3}$ & $194.9 \pm 13.43$ \\
\hline $25-\mathrm{OHD}(\mathrm{ng} / \mathrm{ml})$ & $32.6 \pm 4$ & $29.8 \pm 3.5$ & $25.6 \pm 3.3$ & $18.5^{2} \pm 2.7$ & $37.1 \pm 7.3$ & $24.1 \pm 2.8$ \\
\hline $\mathrm{Ca}(\mathrm{mg} / \mathrm{dl})$ & $9.71 \pm 0.08$ & $9.90 \pm 0.11$ & $9.83 \pm 0.10$ & $10.04^{3} \pm 0.15$ & $10.02 \pm 0.14$ & $9.87 \pm 0.08$ \\
\hline $\mathrm{PO}_{4}(\mathrm{mg} / \mathrm{dl})$ & $4.05 \pm 0.18$ & $4.17 \quad 0.10$ & $3.85 \pm 0.16$ & $3.87 \pm 0.19$ & $3.82^{3} \pm 0.25$ & $3.99 \pm 0.15$ \\
\hline
\end{tabular}

${ }^{1}$ Values shown as mean $\pm \mathrm{SEM}$; numbers in parentheses indicate numbers of subjects.

${ }^{2}$ Paired $t$ test, $P<0.01$

${ }^{3}$ Paired $t$ test, $P<0.05$.

quantitation of total cholesterol, LDL cholesterol $(12,13)$, calcium, phosphate, and 25-OHD $(3,20)$. Normal plasma 25-OHD levels, using a previously described method $(3,20)$ have been $29 \pm 10$ $\mathrm{ng} / \mathrm{ml}$, mean $\pm \mathrm{SD}$.

\section{STATISTICAL ANALYSES}

Comparisons of blood samples were made at different times $v s$. baseline values using paired $t$ analyses; regression analyses were performed on possible correlations between variables; seasonal changes in $25-\mathrm{OHD}$ were compared by Wilcoxon rank tests (22).

\section{RESULTS}

In the 15 children, mean $( \pm \mathrm{SE})$, LDL cholesterol decreased from $221.4 \pm 9 \mathrm{mg} / \mathrm{dl}$ (baseline), to $181 \pm 7$ after $12-14$ months of Colestipol resin, $P<0.01$. Thereafter, LDL cholesterol remained in the $170-190 \mathrm{mg} / \mathrm{dl}$ range (Table 1).

Mean plasma 25-OHD levels appeared to fall slightly and progressively from $32.6 \pm 4 \mathrm{ng} / \mathrm{ml}$ (baseline) to $29.8 \pm 3.5$ at $12-14$ months, to $25.6 \pm 3.3$ at $16-18$ months, and to $18.5 \pm 2.7$ at 18-20 months (Table 1). The decrease in plasma 25-OHD was not significant until 18-20 months (paired $t, P<0.01$ ). After 20 months, plasma 25-OHD levels appeared to increase again and were not significantly different from baseline.

In three patients, plasma 25-OHD levels temporarily fell below normal limits. In patient J. R. (16 years old), plasma 25-OHD levels decreased from $74.8 \mathrm{ng} / \mathrm{ml}$ (baseline) to 20.5 at $12-14$ months, 9.2 at $16-18$ months, and 9.4 at 18-20 months. However, by $22-24$ months, plasma $25-O H D$ levels had returned to normal, $23.2 \mathrm{ng} / \mathrm{ml}$. In patient M.W. (11 years old), plasma 25-OHD was $23.5 \mathrm{ng} / \mathrm{ml}$ at baseline, 35.5 at $12-14$ months, 32 at $16-18 \mathrm{months}$, and 8.8 at $18-20$ months. Levels returned to normal, $16.2 \mathrm{ng} / \mathrm{ml}$, by $22-24$ months. In R.R. ( 20 years old), the baseline $25-\mathrm{OHD}$ value was $25 \mathrm{ng} / \mathrm{ml}$, at $12-14$ months it was 25.7 , but by $18-20$ months, it was decreased to $6.7 \mathrm{ng} / \mathrm{ml}$. At $22-24$, months, $25-$ OHD returned to normal, $21.4 \mathrm{ng} / \mathrm{ml}$. Thus, in these three children, decreased plasma 25-OHD levels were quantitated for 4-6 months, with spontaneous return to normal without change in drug or dietary therapy.

Mean plasma $\mathrm{Ca}$ values were mildly increased after Colestipol therapy was begun, and were significantly elevated at 18-20 months (10.04 vs. $9.71 \mathrm{ng} / \mathrm{dl}$ at baseline). Mean plasma $\mathrm{PO}_{4}$ levels were not significantly different on Colestipol therapy, with the single exception that at 20-22 months plasma $\mathrm{PO}_{4}$ was $3.82 \mathrm{vs}$. $4.05 \mathrm{mg} / \mathrm{dl}$ at baseline $(P<0.05)$. In no subject was serum $\mathrm{Ca}<$ $9 \mathrm{mg} / \mathrm{dl}$ or serum $\mathrm{PO}_{4}<2.5 \mathrm{mg} / \mathrm{dl}$ at any time during the study.

There was no significant correlation between plasma 25-OHD and LDL cholesterol, plasma Ca and plasma 25-OHD, and plasma $\mathrm{PO}_{4}$ vs. 25-OHD (standard regression $P>0.05$ ). Seasonal effects on plasma 25-OHD were not demonstrable. Median 25-OHD levels for winter and spring months were $21-28 \mathrm{ng} / \mathrm{ml}$ and for summer and fall months were $22-30 \mathrm{ng} / \mathrm{ml}$. Values falling below the normal range were evenly distributed among the four seasons.

\section{DISCUSSION}

Since familial hypercholesterolemia can be readily diagnosed in children but does not respond adequately to diet alone $(9$, $11-14,16,27,28)$, increasing attempts have been made to provide drug regimens that effectively and safely lower plasma cholesterol. Organic bile sequestrant anion exchange resins are the most commonly used drugs for use in children and adults; these decrease plasma total and LDL cholesterol in a majority of hypercholesterolemic patients $(8,11-14,16,18,21,28)$. In this study, mean LDL cholesterol levels were significantly reduced $14-22 \%$ below levels achieved on diet alone by Colestipol plus diet. Although LDL cholesterol levels were not thus normalized for all children, this response was comparable to previous reports $(8,11-14,18$, $21,28)$

Since bile acid absorption is decreased by bile sequestrant drugs, malabsorption of fat (15) and fat-soluble vitamins $(6,10,26)$ can occur. In the rat receiving cholestyramine, vitamin $A(10)$ and vitamin $\mathrm{E}(6)$ malabsorption has been demonstrated. However, in children with familial hypercholesterolemia given cholestyramine (12 g/day) (14) or Colestipol (11), 10-15 g/day, plasma vitamin A or E levels were not decreased over a 6-month period of time (12).

The absorption of vitamin $D_{2}$ or vitamin $D_{3}$ in the intestine is bile acid facilitated (24). Absorbed vitamin $D$ is mostly transported in lymph by chylomicrons. Subsequent hydroxylation in the liver yields 25-OHD (2), which is the major circulating vitamin D metabolite in the plasma. Final hydroxylation to 1,25-dihydroxyvitamin $\mathrm{D}$ is performed in the kidney. There appears to be a enterohepatic circulation of 25-OHD (1). Adults with biliary dysfunction have decreased enteric absorption of extrinsic 25OHD (23). Thus, theoretically, the use of a bile acid sequestrant polymer such as Colestipol might result in decreased vitamin $D$ adsorption, or decreased enterohepatic circulation of 25-OHD, both of which might explain the decreased plasma 25-OHD levels.

In the present study, the decrease in plasma $25-\mathrm{OHD}$ in this group of children with familial hypercholesterolemia appeared to be both limited and relatively short lived. Liver 25-hydroxylation in the rat appears to be inhibited by high doses of vitamin D (4). It is unclear whether a compensatory increase in hepatic 25hydroxylation could occur in a situation theoretically predisposing to vitamin $\mathrm{D}$ malabsorption (17). Even in the three children with marked falls in plasma $25-O H D$ to subnormal values, plasma 25 OHD levels reverted to normal in 4-6 months. The fluctuation in plasma 25-OHD levels was not explained by seasonal variation.

The biochemical data referable to calcium and phosphorus are difficult to interpret. Since vitamin $\mathrm{D}$ is particularly important in intestinal absorption of $\mathrm{PO}_{4}$ and $\mathrm{Ca}$, plasma $\mathrm{PO}_{4}$, and $\mathrm{Ca}$ might be decreased in disorders of vitamin $\mathrm{D}$ metabolism. An increase in plasma $\mathrm{Ca}$ and borderline decrease in plasma $\mathrm{PO}_{4}$ levels could be interpreted as indicating a lack of significant effect on $\mathrm{Ca}-\mathrm{PO}_{4}$ metabolism. Furthermore, there was no significant correlation of plasma $\mathrm{Ca}$ or $\mathrm{PO}_{4}$ with plasma 25-OHD levels. In one previous study, using larger doses of cholestyramine $(0.6 \mathrm{~g} / \mathrm{kg} /$ day $)$ for 24-36 months, plasma $\mathrm{PO}_{4}$ levels were decreased (27). It is possible that with larger doses of bile acid-sequestrant resin for prolonged drug therapy, mineral imbalances night occur (27).

\section{CONCLUSION}

Temporary decreases in plasma 25-OHD levels were demonstrated in children with familial hypercholesterolemia receiving Colestipol after approximately a year and a half of therapy. No consistent effect was demonstrable for plasma $\mathrm{Ca}$ and $\mathrm{PO}_{4}$. Long term evaluation of these children would be important in regard to their optimal growth and development. 


\section{REFERENCES AND NOTES}

1. Arnaud, S. B. Goldsmith, R. S., Lambert, F. W., and Go, V. L. W : 25 Hydroxyvitamin $\mathrm{D}_{3}$ : Evidence of an enterohepatic circulation in man. Proc. Soc. Exp. Biol. Med., 149: 570 (1975).

2. Avioli, L. V., and Haddad, J. B.: Vitamin D: Current concepts. Metabolism, 22: 507 (1973).

3. Belsey, R. E., DeLuca, H. F., and Potts, J. T., Jr.: A rapid assay for $25-\mathrm{OH}-$ vitamin $\mathrm{D}_{3}$ without preparative chromatography. J. Clin. Endocrinol. Metab., 38: 1046 (1974).

4. Bhattacharyya, M. H., and DeLuca, H. F.: The regulation of rat liver calciferol25-hydroxylase. J. Biol. Chem., 248: 2969 (1973).

5. Briscoe, A. M., and Ragen, C.: Enhancement of calcium absorption in man by a bile acid sequestrant. Amer. J. Clin. Nutr., 13: 277 (1963).

6. Davies, T., Kelleher, J., Smith, C. L., Walker, B. E., and Lowsowsky, M. S.: Effect of therapeutic measures which alter fat absorption on the absorption of alpha tocopherol in the rat. J. Lab. Clin Med., 79: 824 (1972).

7. Fallat, R. W., Tsang, R. C., and Glueck, C. J.: Hypercholesterolemia and hypertriglyceridemia in children. Preventive Med., 3: 390 (1974).

8. Farah, J. R., Kwiterovich, P. O., Jr., and Neill, C. A.: The dose effect relationship of cholestyramine in children and young adults with familial hypercholesterolemia. Lancet, $i(8002)$ : 59 (1977).

9. Fredrickson, D. S., and Levy, R. I.: Familial hyperlipoproteinemias. In: J. B. Stanbury, J. B. Wyngaarden, and D. S. Fredrickson: The Metabolic Basis of Inherited Disease, Ed. 3, pp. 545-614 (McGraw-Hill Book Co., Inc., New York, 1972).

10. Gagnon, M., and Dawson, A. M.: The effect of bile on vitamin A absorption in the rat. Proc. Soc. Exp. Biol. Med., 127: 99 (1968)

11. Glueck, C. J., Fallat, R. W., Mellies, M., and Tsang, R. C.: Pediatric familial type II hyperlipoproteinemia: therapy with diet and colestipol resin. Pediatrics, 57: 68 (1974).

12. Glueck, C. J., Tsang, R. C. Fallat, R. W., Scheel, D.: Plasma vitamin A and E levels in children with familial type II hyperliproproteinemia during therapy with diet and cholestyramine resin. Pediatrics, 54(1): 51 (1974).

13. Glueck, C. J., Fallat, R. W., and Tsang, R. C.: Hypercholesterolemia and hypertriglyceridemia in children: A pediatric approach to primary atherosclerosis prevention. Amer. J. Dis. Child., 128: 569 (1974)

14. Glueck, C. J., Fallat, R. W., and Tsang, R. C.: Pediatric familial type II hyperlipoproteinemia: Therapy with diet and cholestyramine resin. Pediatrics, 52: 669.(1973).

15. Hashim, S. A., Bergen, S. S., and Van Itallie, T. B.; Experimental steatorrhea

Copyright $(\subset) 1978$ International Pediatric Research Foundation, Inc. $0031-3998 / 78 / 1210-0980 \$ 02.00 / 0$ induced in man by bile acid sequestrants. Proc. Soc. Exp. Biol. Med., 106: 173 (1961).

16. Kwiterovich, P. O., Jr., Fredrickson, D. S., and Levy, R. I.: Familial hypercholesterolemia (one form of familial type II hyperlipoproteinemia): A study of its biochemical, genetic, and clinical presentation in childhood. J. Clin. Invest., 53: 1237 (1974)

17. Mawer, E. B., Backhouse, J., Hill, L. F., Lumb, G. A., DeSilva, P., Taylor, C. M., and Stanbury, S. W.: Vitamin D metabolism and parathyroid function in man. Clin. Sci. Mol. Med., 48: 349 (1975).

18. Parkinson, T. M., Gunderson, K., and Nelson, N. A.: Effects of Colestipol, (U$26,587 \mathrm{~A})$ a new bile acid sequestrant, on serum lipids in experimental animals and man. Atherosclerosis, 11: 531 (1970).

19. Queener, S. F., and Bell, N. H: Treatment of experimental vitamin $D_{3}$ intoxication in the rat with cholestyramine. Clin. Res., 24: 583A (1976).

20. Rosen, J. F., Roginsky, M., Nathenson, G., and Finberg, L.: 25-Hydroxyvitamin D: Plasma levels in mothers and their premature infants with neonatal hypocalcemia. Amer. J. Dis. Child., 127: 220 (1974).

21. Segall, M. M., Lloyd, J. K., Fosbrooke, A. S., and Wolff, O. H.: Treatment of familial hypercholesterolemia in children. Lancet, $i: 641$ (1970).

22. Snedecor, G. W., and Cochran, W. G.: Statistical Methods, Ed. 6 (lowa State College Press, Ames, Iowa, 1967).

23. Stamp, T. C. B.: Intestinal absorption of 25 hydroxycholecalciferol. Lancet, $i$ : 121 (1974).

24. Thompson, G. R., Ockner, R. K., and Isselbacher, J. J.: Effect of mixed unicellar lipid on the absorption of cholesterol and vitamin D into lymph. J. Clin. Invest., 48: 87 (1969).

25. Thompson, W. G., and Thompson, G. R.: Effect of cholestyramine on the absorption of vitamin $\mathrm{D}_{3}$ and calcium. Gut, 10: 717 (1969).

26. Visitine, R. E., Michaels, G. D., Fukayama, G., Conklin, J., and Kinsell, L. W.: Xanthomatous biliary cirrhosis treated with cholestyramine. Lancet, ii: 341 (1961).

27. West, R. J., and Lloyd, J. K.: Effect of cholestyramine on intestinal absorption. Gut, 16(2): 93 (1975).

28. West, R. J., and Lloyd, J. K.: Use of cholestyramine in treatment of children with familial hypercholesterolemia. Arch. Dis. Childhood, 48: 370 (1973).

29. This research was supported in part by the PHS General Clinical Research Center Grant RR 0068-15. A portion of this work was done during Dr. Glueck's tenure as an Established Investigator of the American Heart Association, 1971-1976.

30. Requests for reprints should be addressed to: Dr. Charles J. Glueck, M.D., General Clinical Research Center, University of Cincinnati Medical Center, 234 Goodman Street, Room C2-3, Cincinnati, OH 45267 (USA).

Printed in U.S.A. 